\title{
La buenaventura del carnaval. Tradición oral en un canto narrativo de transmisión moderna*
}

\author{
La buenaventura del carnaval. Oral Tradition in a Modern Song
}

\author{
David Mañero Lozano \\ Universidad de Jaén \\ dmanero@ujaen.es \\ ORCID iD: https://orcid.org/0000-0002-6048-9165
}

RESUMEN: Este estudio, en el que se parte del análisis comparado de casi un centenar de muestras orales de la canción narrativa generalmente conocida como La buenaventura, se propone demostrar que dicha canción, pese a difundirse tardíamente y a través del pliego de cordel, experimentó un interesante proceso de tradicionalización. En particular, la asimilación del lenguaje tradicional es apreciable en el plano del discurso, de la configuración de la intriga y del mensaje fabulístico, así como en las contaminaciones y engarces con otras canciones y romances del repertorio tradicional.

Palabras clave: Buenaventura del carnaval, tradición oral, pliegos de cordel, canción, romances de ciego.

ABSTRACT: This study focuses on the narrative song generally known as La Buenaventura. As I try to show from the comparative analysis of almost a hundred oral samples of different origins, despite spreading recently and through loose folds, this song experimented an interesting process of traditionalization. This is observable at the level

* Agradezco las útiles orientaciones de M. ${ }^{a}$ Jesús Ruiz y la ayuda de José Manuel Fraile, quien me facilitó algunas de las muestras orales más interesantes del corpus analizado. Este estudio se ha beneficiado también de los registros recopilados en el marco de: (a) el proyecto de I+D de Excelencia del Ministerio de Ciencia, Investigación y Universidades "Documentación, tratamiento archivístico digital y estudio lexicológico, histórico-literario y musicológico del patrimonio oral de la Andalucía oriental" (referencia: FFI2017-82344-P), financiado por la Agencia Estatal de Investigación (AEI) y el Fondo Europeo de Desarrollo Regional (FEDER); (b) "Literatura de tradición oral de la comarca de la Sierra de Segura" (referencia: UJA2014/06/27), financiado por el Plan de Apoyo a la I+D+i de la Universidad de Jaén; y (c) "El patrimonio literario oral de la comarca de la Sierra Sur de Jaén. Documentación, tratamiento archivístico digital y estudio" (referencia: 2016/00233/001), financiado por el IEG (Diputación Provincial de Jaén). 
of the discourse, the configuration of the intrigue and the intention, as well as in the contaminations and links with other songs and romances of the traditional repertoire.

Keywords: Buenaventura del carnaval, oral tradition, loose folds, songs, Hispanic Ballads.

\section{PlANTEAMIENTO}

En uno de los últimos ensayos de Catalán (1999), publicado como prólogo a El romancero vulgar y nuevo editado por Salazar, el estudioso se propuso revisar la rígida separación que habitualmente se establece entre los romances tradicionales o tradicionalizados y los romances de cordel oralizados, valorados estos últimos durante mucho tiempo como composiciones fosilizadas, ajenas a la poética tradicional. Según se demuestra mediante el análisis de un conjunto de versiones modernas de Los presagios del labrador, determinados temas de transmisión oral basados en antiguas narraciones "de ciego" presentan la apertura textual característica de los relatos tradicionalizados. En particular, Catalán (1999: xliixlix) ilustra cómo las recreaciones orales reflejan un proceso de "reverbalización de la intriga" (recreación de los pormenores de las escenas, ejemplificaciones formularias, etc.), al tiempo que se observa también una transformación y reducción selectiva de las secuencias narrativas originarias del texto "letrado".

Pese al indudable interés de este acercamiento a los procesos de tradicionalización del pliego, se trata de un campo de estudio inexplorado. En efecto, la mayor parte de los temas carecen de un análisis específico, lo que probablemente se deba a la presunción de que los pliegos se transmiten sin adaptarse al lenguaje tradicional. En palabras del propio Catalán (1999: xxxi), con contadas excepciones, como el ejemplo mencionado de Los presagios del labrador, las composiciones aprendidas de los pliegos "se repiten sin perder, en el curso de su transmisión, su lenguaje literario plebeyo, manteniendo con fidelidad un vocabulario, una sintaxis, unas figuras retóricas, un modo narrativo y una moral muy alejadas de [...] las obras poéticas re-creadas por tradición oral", a lo que añade que "los únicos cambios son deformaciones de lo difícilmente comprensible y olvidos". Como era de esperar, estas circunstancias trajeron consigo el desinterés por la documentación de versiones orales de las canciones derivadas de los pliegos y, en consecuencia, la escasez de muestras de las que extraer conclusiones fiables.

Sin embargo, la posterior diversificación de los intereses científicos y el cambio de mentalidad en lo relativo a la conservación del patrimonio etnográfico, además de los enormes avances tecnológicos de las herramientas de investigación, está propiciando una intensa labor de documentación que nos permite adentrarnos en este campo de estudio vislumbrado por Catalán ${ }^{1}$. En el presente artículo, me propongo estudiar el modo en que la canción narrativa con frecuencia denomi- 
nada La buenaventura, que muy probablemente comenzó a difundirse a través del pliego $^{2}$, se insertó en la rueda de la tradición dando lugar a una evolución comparable a la de otros romances de cordel tradicionalizados. Según acabo de señalar, este proceso de asimilación de la poética tradicional no habría podido estudiarse de no haber logrado acceder a casi un centenar de versiones difundidas en diferentes regiones peninsulares, por lo que conviene dedicar un comentario preliminar al corpus empleado, en el que se contienen 2 muestras de la provincia de Asturias, 1 de Cantabria, 3 de Zamora, 2 de Soria, 1 de Zaragoza, 11 de Burgos, 4 de León, 5 de Palencia, 9 de Valladolid, 1 de Ávila, 2 de Segovia, 1 de Madrid, 1 de Cáceres, 1 de Región Norte (Portugal), 8 de Ciudad Real, 1 de Albacete, 1 de Murcia, 4 de Valencia, 15 de Jaén, 2 de Granada, 13 de Córdoba, 1 de Almería, 3 de Málaga, 1 de Sevilla y 2 de Cádiz. Se trata, pues, de un tema que se extendió por regiones folklóricas muy diversas, lo que nos permitirá indagar las diferencias apreciables entre las áreas peninsulares conservadoras y aquellas más proclives a la innovación. Es de notar, en cualquier caso, el carácter arbitrario de la proporción numérica de versiones recogidas en cada zona, que fundamentalmente responde a la presencia en determinados lugares de investigadores que decidieron no restringir sus encuestas de campo a un repertorio preestablecido. De este modo, la mayoría de las muestras documentadas proceden de los archivos sonoros accesibles en el Corpus de Literatura Oral (Mañero Lozano, 2019-presente; en adelante, $C L O$ ), a las que siguen en número las conservadas en la Fundación Joaquín Díaz, fondos que actualmente se están incorporando también al $C L O$, y las de Manzano Alonso (2003).

Cabe señalar que, con bastante probabilidad, la casi totalidad de las versiones conservadas de La buenaventura, en las que se observa un desarrollo textual prácticamente idéntico, han transmitido una versión "vulgata" del tema, en la que la intriga presenta una forma muy reducida, con escasas posibilidades de generar nuevas variaciones. De este modo, el primer objetivo que me propongo consiste en examinar la configuración del discurso en las secuencias narrativas compartidas por las versiones documentadas, lo que me permitirá determinar el modo en el que el tema se "reverbaliza". Por otra parte, en una segunda fase del análisis, que tendrá también como objeto reconstruir el proceso de oralización de la versión primigenia reflejado en los testimonios cantados, estudiaré los cambios producidos en el tratamiento de la intriga, además de considerar las diferencias apreciables en la dimensión del mensaje o intención. En el tercer apartado, analizaré los engarces y contaminaciones de La buenaventura

\footnotetext{
${ }^{1}$ Un reciente y extenso estado de la cuestión sobre el trabajo de campo en la literatura oral peninsular se ofrece en Mañero Lozano y González Ramírez (2017).

${ }^{2}$ Sobre la figura de la mujer disfrazada en los pliegos de cordel de los ss. XVIII-XIX, remito a Marco (1977: 468-483). A la luz de los testimonios conocidos, que se remontan a comienzos del s. XX, el tema que nos ocupa se documenta únicamente en la tradición oral.
} 
con otras canciones y romances tradicionales, fenómenos que en mi opinión son consecuencia del mismo proceso de oralización. Ofreceré, por último, una hipótesis sobre los posibles desencadenantes de la variación textual, para lo que trataré sobre las circunstancias o contextos de transmisión del tema.

\section{DESARROLLO TEXTUAL Y VARIANTES DEL DISCURSO}

En primer lugar, me ocuparé de analizar las cuatro secuencias narrativas compartidas por la mayoría de las muestras documentadas, al hilo de las cuales examinaré las variantes que ofrecen otras versiones. Esto permitirá observar la evolución experimentada por el tema en el proceso de transmisión oral y, por otro lado, diferenciar los rasgos tradicionales de aquellos otros que, por su naturaleza textual, parecen remontarse a una versión originaria difundida a través del pliego.

Secuencia A. Una mujer se disfraza de gitana y acude a un salón de baile para encontrarse de incógnito con su novio.

En su formulación más recurrente, el texto reza: "Un día de carnaval / de gitana me vestí / y me fui al salón de baile / por ver a mi novio allí'. Otras versiones, en cambio, precisan el momento del encuentro, con referencias a "una noche en carnavales" (n. $\left.{ }^{\circ} 30\right)$, "primer día carnaval" (n. $\left.{ }^{\circ} 11\right)$, "los tres días de carnaval(es)" (n. ${ }^{\text {os }} 12,18,67$, etc.), "vísperas de carnaval" (n. ${ }^{\text {s }} 17 \mathrm{y}$ 21), "domingo carnaval" (n. ${ }^{\text {os }} 4,6,8$, etc.), "domingo de piñata" (n. ${ }^{\text {os }} 3,5,7$, etc.), "lunes de carnaval" (n. ${ }^{\circ}$ 42), "martes de carnaval(es)" (n. ${ }^{\text {os }} 31,50,58$, etc.), además de otras fórmulas habituales en el discurso tradicional como "una mañana temprano" (n. $\left.{ }^{\circ} 24\right)$ o "Una tarde de verano" (n. $\left.{ }^{\circ} 29\right)$, que conviven con soluciones más aisladas como "Una noche de Triana" (n. $\left.{ }^{\circ} 27\right)$.

Más interesantes son las diferencias apreciables en los versos siguientes, en particular en aquellas versiones en las que no se desvela la identidad del individuo con quien se encuentra la mujer disfrazada, de modo que la anagnórisis final tendrá un efecto sorpresivo tanto en el plano de la ficción como para el propio receptor. Así ocurre en aquellas muestras que se limitan a informar de que la protagonista acude al salón de baile "a ver quién había allí" (n. ${ }^{\circ}$ ), ocultamiento que, según veremos, se sostiene hasta el final de la canción. Como es sabido, este escamoteo de los antecedentes narrativos, en este caso de la relación previa entre los personajes, es frecuente en aquellos temas tradicionales en los que el disfraz o el cambio de personalidad o apariencia (debido a los años transcurridos) es clave en el desarrollo de la intriga, como sucede en Don Bueso o en Las señas del esposo. 
Por otra parte, en el extremo contrario a la expresión "a mi novio perseguí" (n. ${ }^{\text {s }} 37,41,42$, etc.) o "pretendí" (n. ${ }^{\circ} 38$ ), contamos con variantes en las que la mujer no toma la iniciativa de buscar al novio, sino que el encuentro se produce de modo fortuito ("y me fui al salón del baile / y estaba mi novio allí,, como sucede en $n .^{\text {os }} 10,11,13$, etc., con variantes en $n .^{\text {os }} 57,62,85$ y 89) o por mediación de terceros ("me convidaron a un baile / por ver a mi novio allí,", n. ${ }^{\text {os }} 59$ y 91$)^{3}$.

Secuencia B. El novio le pide a la mujer disfrazada que le diga la buenaventura.

La mayor parte de las versiones transmiten esta segunda secuencia narrativa con idénticos versos: "Él me dijo: -Gitanilla, / ¿quieres hacer el favor / de decirme con salero / la gracia que tengo yo?" Según es propio del estilo tradicional, en algunas muestras se prescinde del verbo dicendi, con la consiguiente desaparición de la voz narrativa: "Buenos días, gitanilla, / ¿quieres hacerme el favor [...]" (n. ${ }^{\circ} 2$, con variantes en $41,46,48$ y 62 ), parlamento en el que, por virtud de la presunción de pertinencia comunicativa de los versos anteriores, el receptor tiende a inferir que es el novio quien toma la palabra, con lo que no habrá de sorprenderse con la anagnórisis del desenlace. En otros casos, como ya adelantaba, se le esconde hasta el final al receptor la identidad del individuo con quien se encuentra en el baile, a quien se alude en estos términos: "Y me dijo un morenito: / — ¿Quiere hacerme usted el favor [...]?” (n. ${ }^{\circ} 3$ ).

Contamos también con variantes en las que el novio, además de interesarse por la "gracia" o buenaventura mediante diversas formulaciones que no veo de interés enumerar, pregunta por sus defectos ("que me digas claramente / la falta que tengo yo", n. ${ }^{\circ}$, con variantes en n. ${ }^{\circ} 87$ ), a lo que en algunas muestras se añade "para poderla enmendar" (n. ${ }^{\circ}$ ). La curiosidad del pretendiente llega a veces hasta el extremo de preguntar abiertamente por "las novias que tengo yo" (n. $\left.{ }^{\circ} 14\right)$.

Secuencia C. Ella halaga el físico y bondad del individuo, si bien le reprocha que corteje a dos mujeres, una rubia y otra morena, además de augurarle felicidad si se casa con esta e infortunio si escoge a la otra.

El tercero de los segmentos narrativos, tal y como se transmite en la mayoría de las versiones, se desarrolla en los siguientes términos: "—-Tú eres un chico muy guapo / y tienes buen corazón, / pero tienes una falta, / que eres un came-

\footnotetext{
${ }^{3}$ Por lo demás, encontramos sustituciones de términos que no merecen comentarios, si bien ponen de manifiesto el grado de tradicionalización producido, como sucede con el empleo de "me marché" (n. $\left.{ }^{\circ} 5\right)$, "y salí" (n. $\left.{ }^{\circ} 6\right)$, "y entré" (n. ${ }^{\circ}$ 9), etc., en lugar de la formulación más extendida "y me fui".
} 
lador. / Tú camelas dos mujeres, / yo te voy a decir quién son, / una es alta y morena / y otra más rubia que el sol. / Si te casas con la rubia, / has de ser un desgraciado. / Cásate con la morena / y serás afortunado". Las variantes apreciables en esta tercera secuencia afectan, en primer lugar, al plano lingüístico. Por mencionar algunos ejemplos, el individuo es descrito como "hermoso" (n. 46), "lindo mozo" (n. ${ }^{\circ}$ 59), "elegante" (n. $\left.{ }^{\circ} 72\right)$, "hombre alto y moreno, / quebradito de color" (n. $\left.{ }^{\circ} 14\right)$, "un gitano muy guapo / de muy buena condición" (n. ${ }^{\circ}$ 6) o con piropos como "tienes muy bonito el tipo, / te acompaña el corazón" (n. ${ }^{\circ}$ 28), "Eres muy bueno, Paquito" (n. 3), etc.; y la narradora "alta y morena" se representa, entre otros apelativos, como "morenita alta" (n. $\left.{ }^{\circ} 12\right)$, "morena y con garbo" (n. $\left.{ }^{\circ} 45\right)$, "morena graciosa" (n. ${ }^{\text {os }} 2$ y 51$)$, "una morena con gracia / que te roba el corazón" (n. os $\left.^{4}, 9\right)$, "morena como el sol" (n. $\left.{ }^{\circ} 93\right)$, e incluso se identifica con la rubia (n. ${ }^{\circ} 32$ ). Del mismo modo, el reproche "eres un camelador" se expresa en otros términos como "eres un zalamero" (n. $\left.{ }^{\circ} 58\right)$, "muy enamorador" (n. ${ }^{\circ}$ 69), "un calaverón” (n. ${ }^{\text {os }}$ 57, 62 y 64), "sultán del amor" (n. ${ }^{\circ} 83$ ), "falso en el amor" (n. ${ }^{\text {os }} 4,6,42$, etc.), "tienes un defecto, / que te gustan las mujeres" (n. $\left.{ }^{\circ} 43\right)$, "tienes dos comprometidas, / dos engañadas de amor" (n. $\left.{ }^{\circ} 26\right)$, "tienes una falta (o "fama", n. "38) / que ha de ser tu perdición" (n. 9) o "andas por el mundo errante / con una ingrata mujer" (n. ${ }^{\circ} 52$ ), entre otras formulaciones. Llama la atención, por último, cómo la novia disfrazada, en su afán por desplazar a la competidora, la describe en algunas versiones como "rubia y sin color" (n. ${ }^{\text {os }} 20,22,57$, etc.), o bien se vanagloria de sus propios encantos:

Los colores que me salen ni son por ti ni por nadie

Mira qué colores llevo, y si olvidas a la rubia

Me desnudo de gitana y si dices que me quieres no pienses que por ti son; que son míos naturales (n. $\left.{ }^{\circ} 55\right)$.

lo moreno de mi cara,

me desnudo de gitana.

y tiro el mantón también, me voy contigo también (n. ${ }^{\text {os }} 10$ y 11).

En otro orden de cosas, contamos con muestras en las que, tras el consejo de rechazar a la pretendiente rubia, se insertan estas coplas en las que la novia disfrazada justifica su prevalencia:

Todos quieren a la rubia, la rubia no quiere a nadie.

La rubia se va a quedar como un pájaro en el aire.

Si tú sabes elegir, en la vida encontrarás

que todo será más fácil y tendrás felicidad (n. $\left.{ }^{\circ} 43\right)$.

No te faltará dinero, tampoco diversiones,

ni tampoco chavalillos, que los tendrás a montones ( . $^{\circ} 57$ ).

El día que tú te cases, casado con tu mujer,

serás dueño de tu casa y encanto de mi querer

(n. ${ }^{\circ} 58$, con variantes en . $^{\circ} 66$ ). 
En algunas versiones, se añade un parlamento - que denominaré $\mathrm{C} 2$ - entre los sucesos $\mathrm{C}$ y D, que consiste en dilatar el diálogo entre los dos personajes cediendo el turno de palabra al novio para que dé sus impresiones sobre la buenaventura. En general, este confiesa que siente preferencia por la "rubia": "-Yo me caso con la rubia / aunque sea un desgraciado, / pero no con la morena, / aunque sea afortunado" (n. ${ }^{\text {os }} 3,7,8,15,37,92$, etc., con algunas variantes), lo que a veces se justifica en estos términos: "Con la rubia yo me caso / aunque me cueste la vida, / pues es el [?] que me da luz, / esperanza y alegría" (n. ${ }^{\circ} 41$ ); "Ojos azules me gustan, / porque a veces los entorna, / porque a veces los capullos / adornan más que las rosas" (n. " 76); y "La morena vale un duro, / la rubiales vale dos, / yo me tiro a lo más caro / porque es más bueno y mejor" ( . $^{\circ} 78$, con variantes en n. ${ }^{\circ} 90$ ).

En el extremo contrario, el individuo expresa su negativa a casarse con cualquiera de las dos mujeres: "-No me caso con la rubia / aunque sea un desgraciado; / tampoco con la morena, / aunque sea afortunado" (n. ${ }^{\circ}$ 2, con variantes en . $^{\circ} 88$ ); e incluso hace gala de su fama de conquistador y requiebra a la supuesta gitana justo antes de que esta desvele su identidad: "_iVaya una gitanilla linda / que adivina el pensamiento!, / si tú fueras castellana / trataría de casamiento" (n. $\left.{ }^{\circ} 14\right)$. La reacción es la opuesta en aquellas muestras en las que se desprecia el vaticinio: "Esta gitana me mata / con las cosas que me dice; / que te vayas de mi vera, / que no quiero más oírte" (n. ${ }^{\circ} 66$ ).

Otra de las posibles reacciones del individuo consiste en afirmar que, pese a su intención de casarse, ninguna de sus dos pretendidas le corresponde o son inaccesibles ( . $^{\text {os }} 50$ y 53); o bien el galán se jacta de que tiene dos pretendientes: "La morena a mí me quiere / y la rubia está por mí. / Cuando me salgo del baile / las dos se vienen a mí" (n. $\left.{ }^{\circ} 40\right)$, situación que es afrontada con indecisión por el galán (“de esas dos mujeres / yo no sé a quién elegir”, n. ${ }^{\circ} 51$, con variantes en . $^{\circ} 85$ ).

A este parlamento le sigue en algunas muestras una respuesta burlesca -identificada aquí como C3 - en la que la supuesta gitana interpola dos coplas populares registradas desde temprano de forma independiente ${ }^{4}$, que dan paso a los versos finales en los que descubre su identidad. Se trata de estas dos cuartetas:

Piensa el tonto que le quiero porque le miro y me río.

Tengo unos ojos tan pillos, miran a quien yo no miro.

Piensa el tonto que le quiero porque le pongo la silla.

También el torero pone al toro las banderillas

(n. ${ }^{\circ} 40$, con variantes en $32,44^{5}$ ).

\footnotetext{
${ }^{4}$ Sirva como ejemplo la presencia de estas coplas en el repertorio castellano recopilado por Alonso Cortés (1914: 189).

${ }^{5}$ En n. ${ }^{\circ} 80$ nos encontramos versos similares que funcionan como colofón de la secuencia C; mientras que en $n .^{\circ} 83$ se insertan como remate de la secuencia D.
} 
En otra de las versiones (n. ${ }^{\circ} 8$ ), la réplica de la mujer tiene la finalidad de convencer al galán de que la escoja a ella, insistiendo en que vale más que su rival $^{6}$, o pronosticándole los hijos que habrán de tener juntos. Comentaré más adelante los versos, ya que se trata de un posible caso de contaminación con otro tema, del que me interesa tratar por separado. En cualquier caso, según pudo cuantificar Petersen (1972: 169), la introducción de estos nuevos parlamentos, con los que se refuerza la articulación dramática del discurso en detrimento del uso de la voz narrativa, responde a los códigos tradicionales derivados del proceso de transmisión oral.

\section{Secuencia D. La mujer se despide y revela su identidad.}

En su forma más difundida, la narración finaliza con estos versos: “Adiós, Pepe, que me voy / porque mi madre me espera. / Si quieres saber quién soy, / soy tu novia la morena". Entre las versiones que se apartan de esta formulación, algunas ofrecen sustituciones tan expresivas como "Yo me arretiro del baile / porque mi padre me pega" (n. ${ }^{\circ} 28$ ). A la espera de la madre o del padre, la "familia" (n. ${ }^{\text {os }} 40,41,42$, etc.), la "cuadrilla" de amigos (n. ${ }^{\circ} 37$ ) o incluso "la suerte" (n. $\left.{ }^{\circ} 65\right)$, se da como excusa alternativa "porque mi novio me espera" (n. ${ }^{\text {os }} 16,58,73$, etc.), final ambiguo que, en virtud del juego de ocultación de identidad no desvelado hasta el siguiente verso, no deja claro si el término "novio" se refiere a su interlocutor.

De cualquier modo, este anuncio de ruptura con el novio es patente en aquellas versiones donde la mujer le espeta al pretendiente "que otro más guapo me espera" (n. ${ }^{\text {os }} 5$ y 45 ), o le desafía a comprometerse con la amenaza de marcharse en caso contrario con su rival amoroso:

Ahora mismo voy a ver la voluntad que me tienes.

Si no te vienes conmigo, mentira, que no me quieres.

Yo me voy con mi gitano, que al verlo me ha vuelto loca con el sombrerillo de ala ancha y ese purillo en la boca $\left(n .^{\circ} 1\right)$.

En otros casos, se pone el énfasis en la despedida sin mediar ningún pretexto: "Soy tu novia la morena, / la que se muere de amor. / Adiós, Pepe, que me

\footnotetext{
${ }^{6}$ Así en los últimos versos de n. ${ }^{0} 25$, a los que no sigue el episodio de la anagnórisis: "La rubia vale un real, / la morena, una peseta, / cásate con la morena / bien que algo más te llevas". Remito también a n. ${ }^{\circ} 33$ y 71, con variantes. Según hemos visto al tratar sobre la secuencia C2, los mismos términos de comparación se ponen en boca del novio en $n .^{0} 78$. Se trata de una copla registrada con variantes en otras canciones sin relación con la que nos ocupa. Por mencionar un ejemplo, se inserta como parte de la canción festiva 193 del repertorio recogido por Heredia Menchero (2017: 131): "Una rubia vale un duro, / y una morenita dos: / Yo me tiro a lo barato, / rubia de mi corazón".
} 
voy; / adiós para siempre, adiós" (n. ${ }^{\circ} 6$ ); como también en este otro remate en el que se recurre a una fórmula empleada en la lírica tradicional: "soy tu novia la morena, / la que te roba el amor, / y ahora busca quién te quiera, / que ya no te quiero yo" (n. $\left.{ }^{\circ} 9\right)$.

Circula asimismo una interesante versión en la que, además de dilatar el desarrollo de la escena en la que la novia desvela su identidad, mostrando sus manos para comprobar si el individuo la reconoce ${ }^{7}$, la mujer se arrepiente de haber recurrido a la burla del disfraz y promete que no volverá a participar en bailes de máscaras:

Si quieres saber quién soy, Ahora te enseño mis manos; No te puedo dar más señas, Pero ya me has conocido A un baile de mascaritas soy tu novia la morena. míralas, que son pequeñas. que me vas a conocer. mis intenciones malditas. te juro no he de volver (n. $\left.{ }^{\circ} 48\right)$.

Para recalcar el mensaje, esta misma muestra añade tras estos versos un par de coplas costumbristas que, en consonancia con la alusión despectiva al "baile de mascaritas", censura la nueva moda de los calzones con ventilación: "Estos son los calzones / de un señorito. / ¡Uy, qué frío habrá pasado / esta noche el pobrecito! // Tiene ventiladores / que por alante, que por atrás. / Madrecita de mi alma, / cómo está la sociedad" (n. $\left.{ }^{\circ} 48\right)$.

Se observan, por tanto, diferencias patentes tanto en lo que concierne a la posible separación de los novios como en la actitud mostrada por la mujer ante la ruptura, que oscila entre el regodeo de su nueva relación ante el novio burlado, en unos casos, el arrepentimiento, en otros, y aquellas muestras de tono trágico, en las que se interpolan materiales procedentes de la lírica popular:

El día que tú te cases, ese día muero yo, y se juntará en la iglesia mi entierro y tu velación ${ }^{8}$ (n. $\left.{ }^{\circ} 7\right)$.

[Si oyes] tocar campanas, no preguntes quién se ha muerto, que ha sido mi corazón de pena y de sentimiento

(n. ${ }^{\circ} 42$, con variante en $n .^{\circ} 17$ ).

La hoja del laurel mi amor se vino a ver.

¡Ay, qué dolor! Se llevan a tu amor (n. $\left.{ }^{\circ} 59\right)$.

Por lo demás, existe un número significativo de muestras en las que la mujer remata su parlamento con unas palabras de reproche. El carácter sentencioso parece delatar su procedencia de la versión difundida a través del pliego,

${ }^{7}$ Con esta misma función, hay versiones en las que se finaliza la canción mediante estos versos alusivos al juego de ocultamiento de la identidad: "Y no me conoces, / y no me conoces. / No sabes decir quién soy / y como no me conoces, / y como no me conoces / te voy a decir quién soy" (n. $\left.{ }^{\circ} 15\right)$. 
a lo que se añade la carencia de función narrativa, que tal vez explique que se prescinda de la reprensión final en buena parte de la tradición oral. Me refiero a los siguientes versos: "Soy tu novia la morena, / la que te quiso y te amó, / y tú, como eres un pillo, / me armastes esta traición" (n. $\left.{ }^{\circ} 2\right)$, con variantes como "la que en el salón del baile / le has robado (o "manchado", n. ${ }^{\circ}$ 21) el corazón" (n. 8), "pero, como eres muy tuno, / nos quisiste a las dos" (n. ${ }^{\circ}$ 20), "y ahora me has abandonado / por la mujer de la vida" (n. $\left.{ }^{\circ} 60\right)$, entre otras formulaciones que a veces adquieren un mayor desarrollo (como en $\mathrm{n}^{\circ}$ 56, donde la mujer reprocha al individuo su fama de vago y la afición al vino ${ }^{9}$ ).

El desenlace es, por tanto, una de las secuencias narrativas con mayor variabilidad en el proceso de transmisión oral. Se generan diferentes soluciones acordes a los criterios éticos y estéticos de cada comunidad transmisora, e incluso se omite la secuencia en algunas de las muestras documentadas ( . $^{\text {os }} 25$, $27,33,39,43,94$, etc.), o bien se añaden materiales líricos relacionados con la misma "familia" tradicional.

$\mathrm{Al}$ igual que ocurre con $\mathrm{C}$, la secuencia $\mathrm{D}$ se dilata en algunas versiones con un intercambio de pullas entre los personajes, que designaré D2. Así, tras el consabido final "soy tu novia la morena", encontramos este vivo diálogo, en el que se recurre a materiales procedentes del cancionero tradicional ${ }^{10}$ :

\begin{tabular}{|c|c|}
\hline $\begin{array}{l}\text { - Si tú te casas, me caso; } \\
\text { si tú te metes a monja, } \\
\text { - Tienes una mala falta, } \\
\text { que te quitas de la puerta } \\
\text { - Si me quito de la puerta, } \\
\text { lo hago por tus amiguitos, } \\
\text { - Mis amigos bien lo saben } \\
\text { que cuando mientan tu nombre } \\
\text { Una corona de oro, de oro } \\
\text { con un letrero que dice: }\end{array}$ & $\begin{array}{l}\text { si te estás moza, yo mozo; } \\
\text { me meto a religioso. } \\
\text { que te la voy a decir: } \\
\text { en cuanto me ves venir. } \\
\text { amor mío, no es por ti; } \\
\text { que no tengan que decir. } \\
\text { que yo estimo tu persona, } \\
\text { me ponen una corona. } \\
\text { o sobredorada, } \\
\text { por ti muero apasionada" } \text { n. }^{\circ}\end{array}$ \\
\hline
\end{tabular}

\footnotetext{
${ }^{8}$ Son versos recurrentes (sobre todo los dos primeros) en el romance Entierro y boda contrastados (IGRH: 0128): “(Y) El día que tú te cases, / (y) aquel día muero yo. / Se juntarán en la iglesia / mi entierro y tú bendición" (CLO, 0679r).

9 "-Mira, Pepe de mi alma, / yo no me quiero casar / porque me han dicho que eres / un hombre de mal pensar; / que eres flojo y no trabajas, / y así no te quiero yo: / además dice mi prima / que te gusta el alcanfor ['vino']. / Mira, Pepe, mira, Pepe, / te voy a decir la verdad, / que el retrato que me diste / otro novio lo tendrá" (n. ${ }^{\circ} 56$ ).

${ }^{10} \mathrm{Me}$ refiero concretamente a la siguiente canción, que recogí en Ermita Nueva, Jaén: “-Niña, tienes una falta, / que te la voy a decir: / es quitarte de la puerta / apenas me ves venir. // -El quitarme de la puerta, / amor mío, no es por ti; / lo hago por tus amigos, / que no tengan qué decir. // - Mis amigos ya lo saben / que yo adoro a tu persona / y el quitarte de la puerta / es ponerme una corona. // - Si es ponerte una corona, / como si te pones dos. / Yo soy mocita y honrada, / no quiero manchar mi honor" $(C L O, 1506 \mathrm{c})$. Es de notar, por otro lado, que los dos primeros versos citados de $n .^{\circ} 66$, al igual que observamos en $n .^{\circ} 75$, se corresponden con la secuencia narrativa $\mathrm{C} 2$.
} 
La secuencia D2 la encontramos también formulada mediante una repuesta desafiante del galán hacia su rival amoroso: "soy tu novia la morena. / - Si es más guapo que yo, / que salga a la carretera" (n. $\left.{ }^{\circ} 45\right)$.

\section{VARIANTES DE LA INTRIGA}

Además de las variantes del discurso comentadas, el análisis de las versiones conservadas nos permite observar notables diferencias en el desarrollo de la intriga. Me refiero a la aparición de sucesos que no se corresponden con las cuatro secuencias argumentales analizadas.

Aunque no se relata hasta el final de la canción, el primero de estos sucesos diferentes, al que denominaré P1 — con pe de pliego-, se ubica temporalmente con anterioridad al segmento narrativo A, de modo que describe la prehistoria amorosa de los dos personajes que se encuentran en el baile de máscaras. Se trata de una acción indirecta, puesta en boca de la narradora al final de la secuencia narrativa original, ya concluido el segmento D. Esta falta de coincidencia entre la disposición del relato y la secuencia cronológica de los hechos, identificada por Di Stefano (1972: 289-290) como un tipo de estructura narrativa opuesta a la linealidad característica del romancero oral, se asimila más a la complejidad o elaboración "artística" de los pliegos que a la lógica de la oralidad.

Es de notar, por otra parte, que este nuevo segmento desempeña una función retórica, dado que sirve para fundamentar el reproche final de la mujer que, según he sugerido, tal vez proceda de la versión puesta en circulación por el pliego. Así se formula el segmento P1 en esta versión de la localidad malagueña de Cómpeta:
Quince años no tenía
Me pediste relaciones
cuando yo te conocí.
Me cogiste a mis padres $y$ te dijeron que no;
y yo, como te quería, te entregué mi corazón.
Me sacaste de mi casa, me llevaste a una aldea,
hiciste lo que quisiste $\mathrm{y}$ ahora te vas y me dejas
(n. ${ }^{\circ} 4$, con variantes menos extensas en $\mathrm{n} .^{\text {os }} 17,22,47$ y 59 ).

En una de las versiones vallisoletanas (n. 37 ), antes de decir la buenaventura, es decir, entre las secuencias A y B, la protagonista descubre a su novio cortejando a la "rubia": "Al entrar en el salón / con la rubia yo le vi. / Me acerqué adonde estaba / y en seguida dijo así" (n. ${ }^{\circ} 37$ ), lo que enlaza con el parlamento que conocemos de la secuencia B. Se trata, por tanto, de un acontecimiento diferente - $\mathrm{P} 2$ - que se aparta de la intriga relatada en la versión "vulgata". Una variante palentina de este suceso consiste en que el individuo 
requiebra a la novia morena sin reconocerla bajo el disfraz de gitana: "Nada más pisar el baile, / mi novio se me acercó. / Dijo sin reconocerme: / —Estoy loco por tu amor" (n. $\left.{ }^{\circ} 43\right)$. Tanto por el empleo de los verbos dicendi, como por la mayor presencia de la voz narrativa (particularmente en el momento inicial), podría conjeturarse que, al igual que sucede con $\mathrm{P} 1$, la secuencia $\mathrm{P} 2$ es también una reliquia de la versión primigenia que se difundiría mediante el pliego.

Contamos asimismo con una versión leonesa en la que se introduce un acontecimiento - P3 - que amplía la duración temporal de las secuencias narrativas más representadas. Finalizado el diálogo entre los dos personajes, se le da la voz a un narrador que informa de sucesos posteriores al encuentro en el salón de baile: "El joven no hizo caso / y se casó con la rubia, / y al poco de estar casado / al pobre ya le ha pesado" (n. $\left.{ }^{\circ} 46\right)$. Una vez más, la función moralizadora, además de la ubicación de los versos en posición conclusiva, nos sitúan en la órbita de los recursos empleados en los pliegos.

Del mismo modo, al finalizar las secuencias de acontecimientos de la versión vulgata, en una versión zamorana, la narradora da un salto temporal - P4 para informar de que ha recibido una carta de amor, y añade que da por zanjada la relación con el novio al que persiguió de incógnito en el salón de baile:

Carta tengo en el correo, yo no sé de quién será.

Si es de Pepe no la quiero; si es de Juan, venga p'acá.

Carta tengo en el correo, que me cuesta medio duro.

Por saber de mis amores, aunque me costara uno (n. $\left.{ }^{\circ} 50\right)$.

Como en los anteriores casos, habida cuenta del "adelgazamiento" de la intriga que habitualmente trae consigo el proceso de transmisión oral, me inclino a relacionar esta secuencia con la versión primitiva del pliego.

En síntesis, si nos propusiéramos reflejar mediante un esquema facticio todos los posibles desarrollos de la intriga, indicando entre paréntesis las secuencias narrativas solo representadas en algunas versiones, obtendríamos la siguiente serie: (P1), A, (P2), B, C, (C2), (C3), (D), (D2), (P3) y (P4). Según creo, este esquema refleja el notable grado de variabilidad al que está sujeto el tema que nos ocupa, además de la presencia de secuencias artificiosas, en mi opinión procedentes del pliego, de las que el tema prescindió como consecuencia del proceso de transmisión oral. A este particular, quizá sea pertinente señalar cómo las secuencias desechadas por la versión "vulgata" pertenecen a comarcas folklóricas que, en términos generales, son más conservadoras, como es el caso, en cierta medida, de la Andalucía Oriental (P1), y, de modo más evidente, de Valladolid y Palencia (P2), León (P3) y Zamora (P4). 
CONTAMINACIONES Y ENGARCES CON OTRAS CANCIONES Y ROMANCES TRADICIONALES

Existe una canción de temática similar, designada con los títulos La gitanilla, La buenaventura o La buenaventura de la gitanilla, en la que toma también la voz una gitana que se ofrece a leer la mano a un individuo ${ }^{11}$. La mujer le augura fortuna y le pronostica un futuro propicio (ATO, 00567.20), no exento de desgracias en algunas versiones (así en ATO, 00515.13). Después de esto, en el caso de no recibir limosna, la gitana le lanza una serie de maldiciones al individuo $(A T O, 00763.13)$, mientras que en otras versiones se añade una última estrofa en la que toma la voz un narrador en tercera persona que informa de que la gitana se marcha y resalta su atractivo físico (Torres Rodríguez de Gálvez, 1972: 335). La coincidencia de motivos explica que, sin necesidad de contacto entre las dos canciones que nos ocupan, La gitanilla presente paralelismos fraseológicos con La buenaventura del carnaval, como la expresión "que has de ser muy ajortunao" (Torres Rodríguez de Gálvez, 1972: 335), que remeda las fórmulas prototípicas empleadas por las gitanas, o el comienzo "Te la igo resalao, / déjame que te la iga. / Tienes patillas de alambre / y ojillos de siempreviva" (ATO, 00763.13), similar al comienzo de una versión de La buenaventura del carnaval de Guadalix de la Sierra: "Te lo digo, resalao, / si quieres que te lo diga. / Tienes paticas de alambre / y la sangre siempre fría" (n. ${ }^{\circ} 5$ ).

Fuera de estos casos en los que las coincidencias textuales podrían explicarse por poligénesis, hay también versiones de La gitanilla en las que se aprecia una posible contaminación con La buenaventura del carnaval. En una muestra vallisoletana recogida en Campaspero (ATO, 00064.02), un individuo le pide la buenaventura a una gitana, quien después de una serie de augurios le pronostica que no tendrá suerte con "esa tal Marequetilla", que "tiene la muy tunanta / (y) a otro gachín camelao", a lo que añade que "si te casas con ella / has de ser un desgraciado, / y si te casas conmigo / ya verás qué afortunado"12. Aún más evidente es la interpolación de los versos de La buenaventura del carnaval en esta versión de La aparición de la enamorada muerta anexada a El quintado (IGRH: 0176+0168):

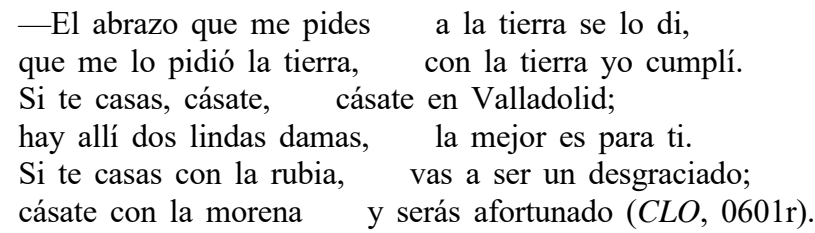

${ }^{11}$ Por el contrario a La buenaventura del carnaval, en el caso de este otro tema tengo constancia de la existencia de una versión trasmitida en pliego.

12 Como dato de interés sobre la difusión de esta canción, la informante indica que la aprendió hacia 1927 de unos montadores suizos que a su vez la habrían escuchado en otra localidad. 
En cuanto a la asimilación de otros temas en la canción que nos ocupa, además del diálogo indicado a propósito de la secuencia $\mathrm{D} 2$, en el que se interpolan materiales procedentes del cancionero popular, hay también versiones de La buenaventura del carnaval en las que cabría sospechar la inserción de dos coplas tomadas de La gitanilla:

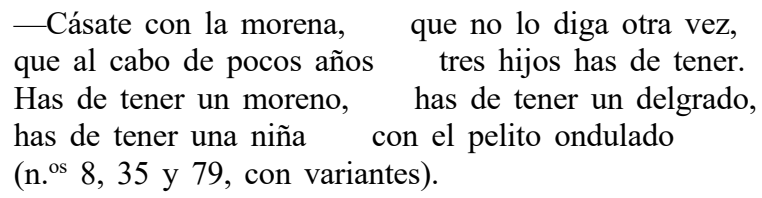

Recordemos, a este propósito, los frecuentes vaticinios de este tipo contenidos en las versiones orales de La gitanilla, que recuerdan los citados versos.

Se documentan, por otra parte, algunas versiones en las que el tema que nos ocupa aparece engarzado a dos romances tradicionales. El primero de estos engarces se registró en dos versiones recopiladas en Torrox (Málaga) por José Manuel Fraile y Marcos León (n. ${ }^{\circ}$ 9) y en la localidad también malagueña de Frigiliana, de manos de estos mismos investigadores y de Ana Ortiz Cortés (n. ${ }^{\circ}$ 59). Se trata de dos muestras de La doncella guerrera con la misma extensión (doce versos con hemistiquios octosilábicos) e idénticas secuencias narrativas, con variantes que afectan al plano del discurso. Pues bien, justo a continuación de que la doncella tome la palabra para lamentarse de su suerte (" $i M a l h a y a$ sea la hora / que al servicio vine yo", n. ${ }^{\circ}$ 9, con la variante "guerra" en n. ${ }^{\circ} 59$ ), se enlaza en ambas versiones con el comienzo de La buenaventura del carnaval ("Un domingo carnaval / de gitana me vestí", etc.). La escucha del registro sonoro de la versión de Torrox (accesible en el $C L O, 0342$ r) nos permite comprobar cómo las informantes enlazan los dos temas de forma natural, sin que se perciba tampoco ningún cambio de ritmo en el acompañamiento de zambomba. Es de notar, por otra parte, cómo el final de un tema y el comienzo del siguiente comparten el uso de la primera persona femenina que asume el protagonismo y que en los dos casos se recurre al disfraz para contar una aventura amorosa. Tales correspondencias, unidas al empleo de una mismo metro y disposición estrófica de la rima, propiciaron este interesante engarce documentado en la provincia de Málaga.

Otro caso de unión de La buenaventura del carnaval con otros temas del romancero, en este caso el de cordel tradicionalizado, nos lo muestra una versión registrada en Pontón Alto (Jaén), en la que se interpreta en segundo lugar La doncella muerta por su amante (IGRH: 5052). A imagen de la fórmula "El domingo carnaval / de gitana me vestí", la segunda de estas canciones narrativas de la versión mencionada comienza: "El domingo carnaval, / señores les voy a contar / lo que le pasó a una niña / por saber muy bien bailar" (n. $\left.{ }^{\circ} 14\right)$. La ubicación en un mismo momento y contexto social (la fiesta de carnaval y 
el baile), además de la temática amorosa, en ambos casos malograda, contribuyen sin duda a justificar el añadido del segundo tema, con el que se aporta una extensión trágica al argumento del primero.

\section{LA “OCASIONALIDAD” MÚltiPle. CONSIDERACIONES SOBRE LOS DESENCADE- NANTES DE LA VARIACIÓN TEXTUAL}

Debido tanto a la escasez de muestras como a la falta de datos contextuales, no es sencillo determinar las circunstancias por las que ciertas canciones inicialmente difundidas a través del pliego experimentaron una mayor evolución durante el proceso de transmisión oral. En efecto, la poca atención prestada por los recopiladores a las circunstancias de la interpretación nos obliga a aventurar conjeturas escasamente refrendadas por las anotaciones de campo. A esto se une la imposibilidad de estudiar un número de versiones tan amplio como el de los romances patrimoniales y vulgares incluidos en las campañas de recopilación auspiciadas en el entorno académico hasta fechas recientes.

En el caso que nos ocupa, habida cuenta de la falta de datos con los que abordar el tema en profundidad, cabe señalar la existencia de tres posibles contextos de transmisión oral que pudieron contribuir a que el texto adquiriese la variación textual que me ocupé de analizar en los apartados anteriores.

En primer lugar, el hecho de que contemos con un amplio conjunto de versiones similares que circularon en zonas muy dispares, unido al empleo de expresiones y clichés ajenos al lenguaje tradicional, revelan una primera fase de difusión a través del pliego, que da lugar a recreaciones posteriores en el entorno doméstico y del trabajo. Este mismo presupuesto, con distintos matices que están en función de las circunstancias de la interpretación, se infiere de la catalogación llevada a cabo por algunos recopiladores modernos. En el Manual de encuesta del romancero andaluz, Atero (2003) clasifica La buenaventura (registro n. ${ }^{\circ}$ 333) dentro del apartado de "galanteos y burlas amorosas", perteneciente a los "romances de cordel o de ciego", criterio secundado en el repertorio de Moreno Moreno (2016). Del mismo modo, Araque Comino (2000: 129) incluye el tema que nos ocupa entre las "coplas de ciego, que generalmente se cantaban acompañando a las labores de la costura".

La clasificación difiere parcialmente en la edición del romancero de Valencia de Rico Beltrán (2010), quien titula el tema "La novia disfrazada de gitana lee la mano al galán", y lo clasifica en el grupo de "Canciones narrativas de tradicionalización moderna", categoría ideada por Diego Catalán que circuló a partir de la edición del romancero de la Isla del Hierro (Trapero, 1985) en referencia a aquellas composiciones de creación moderna en las que se aprecia variabilidad. De este modo, la autora no encuadra el tema dentro del romancero de cordel, al que atribuye una mayor extensión y un mínimo grado de tradicionalidad. 
En otros repertorios, como el de Pliego (2011: 187-188), la muestra recogida se incluye en el apartado dedicado a las canciones de carnaval, clasificación que se justifica precisando que se trata de una canción tradicional, del acervo común, que las comparsas cantaban durante los carnavales por tener una temática bien adaptable al contexto (Pliego 2011: 186). También Gamaza Vázquez (2000: 94) transcribe una versión de Pido (Liébana, Cantabria) en el apartado titulado "Coplas de Carnaval o cascarrillos", además de asegurar que a finales de enero "algunas mujeres [de Pido] se disfrazaban de gitanas que dan la buenaventura" (89). Esto mismo se desprende de las declaraciones de algunos informantes, como sucede a propósito de la muestra n. $^{\circ}$ 31, de Medina del Campo (Valladolid), en la que se indica al finalizar la canción: "Esa se cantaba en los carnavales". De igual modo, la informante de la versión n. ${ }^{\circ}$ 66, registrada en Alcoba (Ciudad Real), recuerda que se cantaba durante esta misma fiesta. La costumbre estuvo muy extendida en nuestra geografía, según se deduce de las anotaciones de 1957 que acompañan la versión $\mathrm{n}^{\circ}$ 56, procedente de Olvera (Cádiz), conservadas en el Fondo de Música Tradicional de la Institución Milà i Fontanals: "Dictó: María Bocanegra Periáñez, de 70 años, modesta posición, de Olvera. La aprendió, siendo niña, de oírla a sus amigas en Olvera. Se usaba durante los días de Carnaval (por parte de las mocitas) por las calles y en los bailes".

Por lo demás, tenemos noticias adicionales que no proporcionan una idea completa del contexto en el que se interpretaba la canción, como es el caso de la muestra n. ${ }^{\circ}$ 36, de Acera de la Vega (Palencia), de la que nos consta el acompañamiento con pandereta; o la versión . $^{\circ}$ 53, recogida en San Vitero (Zamora, España), que según el recuerdo de la informante se cantaba en rondas.

Otro posible contexto en el que se interpretaba de La buenaventura del carnaval se desprende de la clasificación llevada a cabo por Pelegrín (1999: 244), quien cataloga como canción de corro infantil ( $\mathrm{n}^{\circ} 062$ de su repertorio) el tema titulado Gitanilla de la buena ventura, que a juzgar por la transcripción de los versos iniciales ("El domingo de Piñata / de gitana me vestí") se corresponde con una versión del tema que nos ocupa.

\section{CONCLUSIONES}

El análisis ofrecido en estas páginas ha mostrado cómo La buenaventura del carnaval, pese a tratarse de un tema incorporado tardíamente a la tradición y a pesar también de proceder de una versión originariamente difundida a través del pliego de cordel, presenta una incuestionable variabilidad en el plano del discurso, del tratamiento de la intriga e incluso del mensaje o intención, además de ofrecer una amplia casuística de contaminaciones y engarces con otras canciones y con romances tradicionales como La aparición de la enamorada muerta 
(IGRH: 0168), La doncella guerrera (IGRH: 0231) y La doncella muerta por su amante (IGRH: 5052). Son circunstancias que presumiblemente se vieron favorecidas por la diversidad de contextos en los que se interpretó la canción.

Por otro lado, más allá del estudio concreto de La buenaventura del carna$v a l$, en el presente trabajo he intentado poner de manifiesto la conveniencia de dedicar mayor atención a determinados temas que, tal vez debido a su escasa antigüedad, han sido prejuzgados como manifestaciones al margen de la tradición oral. A este propósito, considero que el método empleado en este estudio, articulado en torno a un esquema de representación en el que diferenciamos entre las secuencias narrativas procedentes del pliego y aquellas otras resultantes del proceso de oralización, ofrece un modelo que podría aplicarse con resultados provechosos al resto de los temas derivados de los pliegos de cordel. Según es patente, en los últimos años empezamos a contar con un volumen de muestras orales y unos medios de investigación que nos permiten estudiar con mayores garantías de fiabilidad los procesos de asimilación de la poética tradicional en un amplio repertorio de canciones y romances procedentes de los pliegos, tarea a la que espero haber contribuido con el presente estudio.

\section{ANEXO. MUESTRAS ORALES}

N. ${ }^{\circ}$ 1: Priego de Córdoba (Córdoba) (Alcalá Ortiz, 2006: 109-110)

N. . 2: Castellar de Santiago (Ciudad Real) (Pliego, 2011: 187-188)

N. ${ }^{\circ}$ 3: Alcázar de San Juan (Ciudad Real) (Araque Comino, 2000: 130-131)

N. ${ }^{\circ}$ 4: Cómpeta (Málaga) $(C L O, 0325 \mathrm{r})$

N. ${ }^{\circ}$ 5: Guadalix de la Sierra (Madrid) $(C L O, 0326 \mathrm{r})$

N. ${ }^{\circ}$ 6: Pozo de los Frailes (Almería) $(C L O, 0327 \mathrm{r})$

N. ${ }^{\circ}$ 7: Estepa (Sevilla) $(C L O, 0313 \mathrm{r})$

N. ${ }^{\circ}$ 8: Lezuza (Albacete) $(C L O, 0328 \mathrm{r})$

N. ${ }^{\circ}$ 9: Torrox (Málaga) $(C L O, 0342$ r)

N. ${ }^{\circ}$ 10: Jamilena (Jaén) $(C L O, 0010 \mathrm{r})$

N. ${ }^{\circ}$ 11: Jamilena (Jaén) $(C L O, 0055 \mathrm{r})$

N. ${ }^{\circ}$ 12: Mengíbar (Jaén) (CLO, 0061r)

N. ${ }^{\circ}$ 13: Torres de Albanchez (Jaén) (CLO, 0157r)

N. ${ }^{\circ}$ 14: Pontón Alto (Jaén) (CLO, 0179r)

N. ${ }^{\circ}$ 15: Ochavillo del Río, Fuente Palmera (Córdoba) (Moreno Moreno 2016: 759)

N. ${ }^{\circ}$ 16: La Victoria (Córdoba) (Moreno Moreno 2016: 760)

N. ${ }^{\circ}$ 17: El Rinconcillo, La Carlota (Córdoba) (Moreno Moreno 2016: 760-761)

N. ${ }^{\circ}$ 18: Fuente Obejuna (Córdoba) (Moreno Moreno 2016: 761)

N. ${ }^{\circ}$ 19: Hinojosa del Duque (Córdoba) (Moreno Moreno 2016: 762)

N. ${ }^{\circ}$ 20: Villanueva de Córdoba (Córdoba) (Moreno Moreno 2016: 762-763)

N. ${ }^{\circ}$ 21: Carcabuey (Córdoba) (Moreno Moreno 2016: 763)

N. ${ }^{\circ}$ 22: Villaharta (Córdoba) (Moreno Moreno 2016: 763-764)

N. ${ }^{\circ}$ 23: Hinojosa del Duque y Belalcázar (Córdoba) (Moreno Moreno 2016: 764)

N. ${ }^{\circ}$ 24: Algallarín (Córdoba) (Moreno Moreno 2016: 765) 
N. 25: Belmez (Córdoba) (Moreno Moreno 2016: 765).

N. 26: Recogido en Pido, Liébana (Cantabria) (Gamaza Vázquez 2000: 94)

N. ${ }^{\circ}$ 27: Lorca (Murcia) (Guerrero Ruiz y López Valero 1996: 110)

N. ${ }^{\circ}$ 28: Algeciras, Campo de Gibraltar (Cádiz) (Ruiz Fernández 1995: 75)

N. ${ }^{\circ}$ 29: Rebanal de las Llantas (Palencia) (ATO, 00898 05)

N. ${ }^{\circ}$ 30: Pinarnegrillo (Segovia) (ATO, 00490 29)

N. ${ }^{\circ}$ 31: Medina del Campo (Valladolid) (ATO, 00165 02)

N. 32 : La Mudarra (Valladolid) (ATO, 00335 16)

N. ${ }^{\circ}$ 33: Castrocalbón (León) (ATO, 00113 14)

N. ${ }^{\circ}$ 34: Cervatos de la Cueza (Palencia) (ATO, 00697 06)

N. ${ }^{\circ}$ 35: Navalosa (Ávila) (Martín Sánchez, 2008: 173).

N. 36: Acera de la Vega (Palencia) (ATO, 00746A 06)

N. ${ }^{\circ}$ 37: Quintanilla de Trigueros (Valladolid) (ATO, 00559 25)

N. ${ }^{\circ}$ 38: Morales del Rey (Zamora) (ATO, 00743 46)

N. ${ }^{\circ}$ 39: Carazo (Burgos) (ATO, 0037403 )

N. ${ }^{\circ}$ 40: Cogeces del Monte (Valladolid) $(C L O, 0784 \mathrm{r})$

N. ${ }^{\circ}$ 41: Aldeamayor de San Martín (Valladolid) (ATO, 00091 13)

N. ${ }^{\circ}$ 42: Gallegos de Hornija (Valladolid) (ATO, 00563 38)

N. ${ }^{\circ}$ 43: Congosto de Valdavia (Palencia) (ATO, 00762 12)

N. ${ }^{\circ}$ 44: Quintanilla de Onésimo (Valladolid) (ATO, 00166A 49)

N. ${ }^{\circ}$ 45: Orgiva (Granada) (Escribano Pueo et al., 1995: 135)

N. ${ }^{\circ}$ 46: Cacabelos (León) (ATO, 00592 22)

N. ${ }^{\circ}$ 47: Gójar (Granada) (Escribano Pueo et al., 1995: 136)

N. ${ }^{\circ}$ 48: Villabrágima (Valladolid) (ATO, 00035 28)

N. ${ }^{\circ}$ 49: Cabreros del Río (León) (ATO, 00522 04)

N. ${ }^{\circ}$ 50: Palazuelo de las Cuevas (Zamora) (ATO, 00204 13)

N. ${ }^{\circ}$ 51: Valbuena de Duero (Valladolid) (ATO, 00617 03)

N. ${ }^{\circ}$ 52: Cisneros (Palencia) (ATO, 00651A 24)

N. ${ }^{\circ}$ 53: San Vitero (Zamora) (ATO, 00174 01)

N. ${ }^{\circ}$ 54: Chañe (Segovia) (ATO, 00384A 16)

N. ${ }^{\circ}$ 55: Almazán (Soria) (Fondo de Música Tradicional de la Institución Milà i

Fontanals, M17-200 <http://musicatradicional.eu/es/piece/17126>)

N. ${ }^{\circ}$ 56: Olvera (Cádiz) (Fondo de Música Tradicional de la Institución Milà i

Fontanals, M57-055 <http://musicatradicional.eu/es/piece/14968>)

N. ${ }^{\circ}$ 57: Valtorres (Zaragoza) (Bernal Bernal, 2003: 436)

N. ${ }^{\circ}$ 58: Belén (Cáceres) (CLO, 364r)

N. ${ }^{\circ}$ 59: Frigiliana (Málaga) (Fraile Gil, 2013: 88-89)

N. ${ }^{\circ}$ 60: Herencia (Ciudad Real) (Heredia Menchero, 2017: 44)

N. ${ }^{\circ}$ 61: Herencia (Ciudad Real) (Heredia Menchero, 2017: 413-414)

N. ${ }^{\circ}$ 62: Benaguassil (Valencia) (Rico Beltrán, 2010: 780)

N. ${ }^{\circ}$ 63: Sant Joan d’Ėnova (Valencia) (Rico Beltrán, 2010: 781)

N. ${ }^{\circ}$ 64: Quart de Poblet (Valencia) (Rico Beltrán, 2010: 782)

N. ${ }^{\circ}$ 65: Valencia (Valencia) (Rico Beltrán, 2010: 783)

N. ${ }^{\circ}$ 66: Alcoba (Ciudad Real) (CLO, 0512r)

N. ${ }^{\circ}$ 67: Mures, Alcalá la Real (Jaén) $(C L O, 0381$ r)

N. ${ }^{\circ}$ 68: Alcaudete (Jaén) (CLO, 0392r)

N. ${ }^{\circ}$ 69: Valdepeñas de Jaén (Jaén) $(C L O, 0403 r)$

N. ${ }^{\circ} 70$ : Valdepeñas de Jaén (Jaén) $(C L O, 0446 r)$ 
N. ${ }^{\circ}$ 71: Pendueles, Llanes (Asturias) $(C L O, 0463 r)$

N. ${ }^{\circ} 72$ : Noguerones (Jaén) (CLO, 0878r)

N. ${ }^{\circ}$ 73: Sabariego (Jaén) (CLO, 0926r)

N. ${ }^{\circ}$ 74: Daimiel (Ciudad Real) $(C L O, 993 \mathrm{r})$

N. ${ }^{\circ}$ 75: Los Pozuelos de Calatrava (Ciudad Real) $(C L O, 1017 \mathrm{r})$

N. ${ }^{\circ}$ 76: Calzada de Calatrava (Ciudad Real) (CLO, 1068r)

N. ${ }^{\circ}$ 77: Carbajal de Rueda (León) (Puerto, 2013: 184)

N. ${ }^{\circ}$ 78: Itero del Castillo (Burgos) (Manzano Alonso, 2003: 619)

N. ${ }^{\circ}$ 79: Ahedo del Butrón (Burgos) (Manzano Alonso, 2003: 620-621)

N. ${ }^{\circ}$ 80: Cabezón de la Sierra (Burgos) (Manzano Alonso, 2003: 621)

N. ${ }^{\circ}$ 81: Rupelo (Burgos) (Manzano Alonso, 2003: 623)

N. ${ }^{\circ}$ 82: Valmala (Burgos) (Manzano Alonso, 2003: 624)

N. ${ }^{\circ}$ 83: Berlangas de Roa (Burgos) (Manzano Alonso, 2003: 625)

N. ${ }^{\circ}$ 84: Cilleruelo de Abajo (Burgos) (Manzano Alonso, 2003: 626)

N. ${ }^{\circ}$ 85: Huerta de Rey (Burgos) (Manzano Alonso, 2003: 627)

N. ${ }^{\circ}$ 86: Tubilla del Lago (Burgos) (Manzano Alonso, 2003: 628)

N. ${ }^{\circ}$ 87: Royuela de Río Franco (Burgos) (Manzano Alonso, 2003: 629)

N. ${ }^{\circ}$ 88: Trévago (Soria) (ATO, 00370 11)

N. ${ }^{\circ}$ 89: Villamexín, Proaza (Asturias) (Torre García, 2010: 227)

N. ${ }^{\circ}$ 90: Rio de Onor, Braganza (Región Norte, Portugal) (Dias, 1981: 241)

N. ${ }^{\circ}$ 91: Borrallo, Gaena (Córdoba) (Trujillo Pacheco, 2017: 151-152)

N. ${ }^{\circ}$ 92: El Rincón, Santo Tomé (Jaén) (CLO, 1443r)

N. ${ }^{\circ}$ 93: La Iruela (Jaén) $(C L O, 1454 \mathrm{r})$

N. ${ }^{\circ}$ 94: Arroyo Frío (Jaén) $(C L O, 1552 \mathrm{r})$

N. ${ }^{\circ}$ 95: Fontanar (Jaén) $(C L O, 1553 \mathrm{r})$

\section{BIBLIOGRAFÍA}

Alcalá Ortiz, Enrique (2006): Cancionero popular de Priego. Poesía cordobesa de cante y baile, 8 vols., reedición, [Priego de Córdoba], Ediciones Huerta Palacio (Cuadernos de Literatura), vol. VII.

Alonso Cortés, Narciso (1914): "Cantares populares de Castilla, recogidos por Narciso Alonso Cortés (1-3152)", Revue hispanique, 32, 81, pp. 87-304.

Araque Comino, Esther (2000): "Contribución al Cancionero de Alcázar de San Juan (1)", Revista de Floklore, 232, pp. 127-138.

Atero Burgos, Virtudes (2003): Manual de encuesta del romancero de Andalucía. Catálogo-Índi$c e$, Cádiz, Universidad de Cádiz.

ATO = Archivo de Tradición Oral, Joaquín Díaz, <http://www.funjdiaz.net/fono1.php>

Bernal Bernal, Sergio (2003): Música y tradición de un pueblo aragonés: Valtorres [en línea]; Zaragoza, Diputación General de Aragón, Archivos de tradición oral y grabaciones sonoras de Aragón (SIPCA), <http://etno.patrimoniocultural.aragon.es/valtorres2/2mocedad.htm>.

Catalán, Diego (prólogo) (1999): Flor Salazar (ed.), El romancero vulgar y nuevo, Madrid, Fundación Ramón Menéndez Pidal / Seminario Menéndez Pidal.

CLO $=$ Corpus de Literatura Oral, David Mañero Lozano (dir./ed.) (2019-), Jaén, Universidad de Jaén, <https://corpusdeliteraturaoral.ujaen.es/>.

Dias, Jorge (1981): Rio de Onor: comunitarismo agro-pastoril, Lisboa, Editora Presença.

Di Stefano, Giuseppe (1972): "Tradición antigua y tradición moderna. Apuntes sobre poética e historia del Romancero", en Diego Catalán y Samuel Armistead (eds.), El romancero en la 
tradición oral moderna, I Coloquio Internacional, Madrid, CSMP-Universidad de Madrid, pp. 277-296.

Escribano Pueo, María Luz, Fuentes Vázquez, T. y Romero López, A. (eds.) (1995): Romancero granadino de tradición oral: segunda flor, Granada, Universidad de Granada, 1995.

Fraile Gil, José Manuel (2013): Música y tradición oral en Frigiliana (Málaga). Libro homenaje a Ana Pelegrín, Madrid, Gráficas Iglesias.

Gamaza Vázquez, Antonio (2000): Canciones y romances de Liébana. Recopilación etnomusicológica, Santander, Universidad de Cantabria.

Guerrero Ruiz, Pedro, y López Valero, Amando (1996): Poesía popular murciana, Murcia, Universidad de Murcia.

Heredia Menchero, José Vicente (2017): Literatura oral y cultura popular de Villarta de San Juan y de la Comarca de La Mancha, Tesis doctoral, Alcalá de Henares, Universidad de Alcalá.

Manzano Alonso, Miguel (2003): Cantos narrativos, en Cancionero popular de Burgos, 7 vols., Publicaciones de la Excma. Diputación Provincial de Burgos, vol. 3.

Mañero Lozano, David y David González Ramírez (coords.) (2017). "Los paisajes de la voz. Literatura oral e investigaciones de campo", Boletín de Literatura Oral, número extraordinario 1.

Marco, Joaquín (1977): Literatura popular en España en los siglos XVIII y XIX (una aproximación a los pliegos de cordel), 2 vols., Madrid, Taurus.

Martín Sánchez, David (2008): "El carnaval de Navalosa: estudio etnográfico-musical", Revista de Folklore, 329, pp. 168-174.

Moreno Moreno, Luis (2016): Romancero de Córdoba: Transcripción y estudio musical de los romances recogidos en la provincia de Córdoba, Tesis Doctoral, Córdoba, Universidad de Córdoba.

Pelegrín, Ana (1999): Catálogo de retahílas y canciones infantiles en Andalucía, en P. Piñero, E. Baltanás y A. Pérez Castellano (eds.), Romances y canciones en la tradición andaluza, Sevilla, Fundación Machado, pp. 217-290.

Petersen, Suzanne (1972): "Cambios estructurales en el Romancero tradicional”, en Diego Catalán y Samuel Armistead (eds.), El romancero en la tradición oral moderna, I Coloquio Internacional, Madrid, CSMP-Universidad de Madrid, pp. 167-179.

Pliego, Agustín Clemente (2011): Estudio de la literatura folklórica de Castellar de Santiago (C. Real), Tesis doctoral, Madrid, Universidad Complutense de Madrid.

Puerto, José Luis (2013): Rumor de la palabra. Tradiciones orales en la comarca leonesa de Rueda, León, Universidad, Área de Publicaciones.

Rico Beltrán, Amparo (2010): El romancero en Valencia, pervivencia de una tradición oral (catálogo y estudio), Valencia, Museo Valenciano de Etnología-Diputación de Valencia.

Ruiz Fernández, María Jesús (1995): La tradición oral del Campo de Gibraltar, Cádiz, Diputación de Cádiz.

Torre García, Antonio Alonso de la (2010): Dichos, cuentos ya otres narraciones recoyíes en Villamexín (Proaza), Oviedo, Academia de la Llingua Asturiana.

Torres Rodríguez de Gálvez, M. ${ }^{a}$ de los Dolores (1972): Cancionero popular de Jaén, Jaén, Instituto de Estudios Giennenses.

Trapero, Maximiano (1985): Romancero de la Isla del Hierro, Madrid, SMP-Cabildo Insular de El Hierro.

Trujillo Pacheco, Víctor M. (2017): Música y tradición oral en Gaena y su entorno, Pamplona, Lamiñarra.

Fecha de recepción: 24 de enero de 2018

Fecha de aceptación: 2 de marzo de 2018 